\title{
Management of adult concealed penis using a meshed, split-thickness skin graft
}

\author{
Aaron Boonjindasup, MD; Michael Pinsky, MD; Carrie Stewart, MD; Landon Trost, MD, ${ }^{-1,2}$ \\ Abigail Chaffin, MD, FACS, ${ }^{3}$ David Jansen, MD, FACS, ${ }^{3}$ Wayne Hellstrom, MD, FACS ${ }^{1}$
}

'Department of Urology, Tulane University School of Medicine, New Orleans, LA, United States; ${ }^{2}$ Department of Urology, Mayo Clinic, Rochester, MN, United States; ${ }^{3}$ Department of Plastic Surgery, Tulane University School of Medicine, New Orleans, LA, United States

Cite as: Can Urol Assoc J 2016;10(11-12):E407-11. http://dx.doi.org/10.5489/cuaj.3787 Published online November 10, 2016.

\section{Abstract}

Introduction: Concealed penis $(\mathrm{CP})$ is a rare problem faced by urologists and plastic surgeons. CP occurs secondary to trauma, obesity, or infection. Surgical treatment is individualized and based on patient and provider variables. We aim to review our recent experience using meshed split-thickness skin grafting (STSG) for CP management.

Methods: A retrospective review was performed on patients who underwent STSG for CP at our institution. Records were reviewed for demographic, operative, and postoperative variables. Preoperative and postoperative photos were obtained to monitor cosmetic results.

Results: Eleven patients underwent CP release with meshed STSG placement. All cases showed improved functional phallic length and good cosmetic results, regardless of etiology.

Conclusions: STSG is a viable option for penile coverage for management of this difficult-to-treat CP population. This primary or salvage modality offers excellent cosmetic results and may be used following prior reconstructive attempts.

\section{Introduction}

Concealed penis $(\mathrm{CP})$ in the adult population is a rare and challenging condition and is frequently managed in a multidisciplinary fashion. Unlike the pediatric population, adult $\mathrm{CP}$ is more commonly an acquired condition secondary to trauma, obesity, infection, or following surgery. In addition to physical impairments, CP may also result in psychological anxiety and distress.

The optimal management strategy for CP in adults is poorly documented, with surgical reconstruction performed based on the extent of penile and scrotal skin defect, etiology of $\mathrm{CP}$, and provider experience. Given the relative infrequency of $\mathrm{CP}$ in adults, limited data exist regarding the optimal reconstruction procedure for resected penile skin.
In 1993, Donatucci and Ritter first reported a treatment algorithm of penile skin coverage based on their series of adult $\mathrm{CP}$ reconstruction. ${ }^{1}$ Ten years later, Pestana et al revisited the subject and provided a thorough overview of the literature and current techniques available for adult CP. ${ }^{2}$ Higuchi et al made great strides in classifying the problem of $\mathrm{CP}$ and presented a well-organized updated treatment algorithm based on Donatucci and Pestana's earlier works. ${ }^{3}$ Although surgical techniques vary, the primary goal of treatment is to improve the patient's quality of life, including retentive or dysfunctional voiding habits, sexual function, and overall genital aesthetics.

Full-thickness skin grafts (FTSG) have been advocated in the use of penile coverage in order to minimize primary contraction when compared to split-thickness skin grafts (STSG). However, the presence of hair follicles within the dermis of FTSG also makes this a poor option for penile grafting. Donor site morbidity is minimized with STSG.

The majority of disease processes that cause CP are isolated to the skin and external subcutaneous tissue layers, sparing the tissue beneath the deep (Buck's) penile fascia. Excision of the diseased tissue is commonly required, with the extent of resection varying by disease etiology (i.e., panniculectomy or escutcheonectomy for obesity). In patients with lymphedema, a more extensive excision may be required to assure complete removal of affected tissue. ${ }^{4}$

Several techniques for penile skin reconstruction have been reported. Among men with prominent suprapubic adiposity, Alter and Ehrlich described performing suprapubic dermatolipectomy with fixation of the penopubic subdermis to the rectus fascia. ${ }^{5,6}$ Penile and scrotal skin coverage was subsequently achieved using Z-plasty techniques without need for skin grafting.

The use of STSG for the correction of CP and resurfacing of the penile shaft has been described in pediatric and trauma series, with successful outcomes reported. ${ }^{7,8}$ STSG has been used by plastic surgeons for many years and allows for the resurfacing of large wounds. Tang et al reported outcomes from five acquired CP patients undergoing escutch- 
eonectomy and scrotoplasty with STSG placement and fibrin glue application. ${ }^{9}$ Similarly, Black et al reported use of a meshed STSG for extensive penile skin loss coverage in nine patients and noted successful graft uptake in all patients, with excellent esthetic results. ${ }^{10}$

Given the relative lack of literature on CP management, the objective of this communication is to report outcomes of men undergoing meshed STSG placement for penile skin coverage during $\mathrm{CP}$ reconstruction.

\section{Methods}

A retrospective chart review was performed on patients who underwent reconstruction of CP with STSG placement from 2000-2013. Patient records were reviewed for demographic data, including age at surgery, etiology of $\mathrm{CP}$, and medical comorbidities. Intraoperative variables were tabulated, including graft size, site of graft harvest, and concurrent penile prosthesis. Length of followup was assessed based on the patients' most recent clinical appointment. Pre- and postoperative images were reviewed to compare and report cosmetic results.

\section{Surgical technique}

Patients underwent CP release, which included several key steps:

1. Excision of the diseased penile tissue or surrounding subcutaneous tissue and fat to release $\mathrm{CP}$

2. Harvesting of the skin graft with electric dermatome

3. Graft preparation with micro-fenestrated meshing using a Zimmer device (Zimmer MeshGraft II, Warsaw, IN, U.S.)

4. Fixation of subcutaneous suprapubic dermis to penile suspensory ligament

5. Placement of negative pressure wound vacuum to the graft site
Patients are customarily placed in a low lithotomy position with the genitalia, pannus, and bilateral thighs included in the operative field. A Foley catheter is customarily placed to assist in urethral identification during tissue excision and, on occasion, a penile glanular traction suture to facilitate dissection and mobilization. Excess penile soft tissue is subsequently resected with caution to avoid injuring the superficial neurovascular structures. Additional scar tissue and ligamentous attachments are identified and resected to provide further penile mobility.

Skin grafts from the lateral thigh or abdominal pannus are harvested prior to panniculectomy. An electric dermatome (Zimmer Electric Dermatome, Warsaw, IN, U.S.) is preferred, with graft depths set to $0.012-0.018$ inches. The use of the dermatome provides a more consistent graft depth compared to manual extraction, with split thickness used to expose the superficial dermal plexus and aid in graft inosculation. To minimize hemorrhage, $1 \%$ lidocaine with epinephrine may be instilled subcutaneously at the graft site prior to dissection.

The graft is then meshed with fenestrations using a Zimmer-type mesher (Zimmer MeshGraft II Warsaw, IN, U.S.) in a 1.5:1 expansion ratio. The graft is then applied to the denuded area with the dermal side facing the penile shaft tissue and sutured in place with interrupted sutures.

As needed, advancement sutures may be placed to secure the proximal penile shaft to the rectus fascia or pubic symphysis to prevent phallus retraction. Optimal placement is performed at positions to avoid injury to the dorsal neurovascular bundle. A negative-pressure wound vacuum is placed around the graft bed and connected to low continuous suction $(75 \mathrm{mmHg}$ ) to provide optimal drainage of the wound bed. Wound vac therapy is maintained for $7-10$ days to optimize graft yields.

\begin{tabular}{|c|c|c|c|c|c|}
\hline Patient no. & $\begin{array}{l}\text { Age at DOS } \\
\text { (years) }\end{array}$ & Preoperative Dx & $\begin{array}{l}\text { Graft size } \\
\text { (sq cm) }\end{array}$ & IPP & $\begin{array}{l}\text { Other procedures } \\
\text { performed }\end{array}$ \\
\hline 1 & 55 & Urethral stricture, severe concealed penis & 180 & No & Liposuction \\
\hline 2 & 64 & Hidden penis syndrome, secondary to circumcision & 80 & Yes & $\begin{array}{l}\text { Release of fundiform } \\
\text { ligament }\end{array}$ \\
\hline 3 & 28 & Balanitis, obesity & 80 & No & No \\
\hline 4 & 54 & $\begin{array}{l}\text { Lymphedema, concealed penis, morbid obesity; penis buried } \\
\qquad 8 \text { inches into fat }\end{array}$ & 90 & No & $\begin{array}{l}\text { Panniculectomy, } \\
\text { scrotectomy }\end{array}$ \\
\hline 5 & 43 & Shortened from circumcision, cicatricial penile adhesions & 140 & No & No \\
\hline 6 & 43 & BXO of foreskin and cephalad portion of scrotum & 120 & No & Partial panniculectomy \\
\hline 7 & 45 & Penile skin necrosis secondary to IPP & 400 & No & No \\
\hline 8 & 69 & Hidden penis syndrome and dependent panniculus & 80 & No & Dermolipectomy \\
\hline 9 & 40 & Concealed penis, scrotal lymphedema, scrotal hidradenitis & 24 & No & Scrotectomy \\
\hline 10 & 65 & Foreign body in penile soft tissue; silicone injections for girth & 103 & No & Excision of foreign body \\
\hline 11 & 56 & Hidden penis, panniculus adiposus & 130 & No & Panniculectomy \\
\hline
\end{tabular}




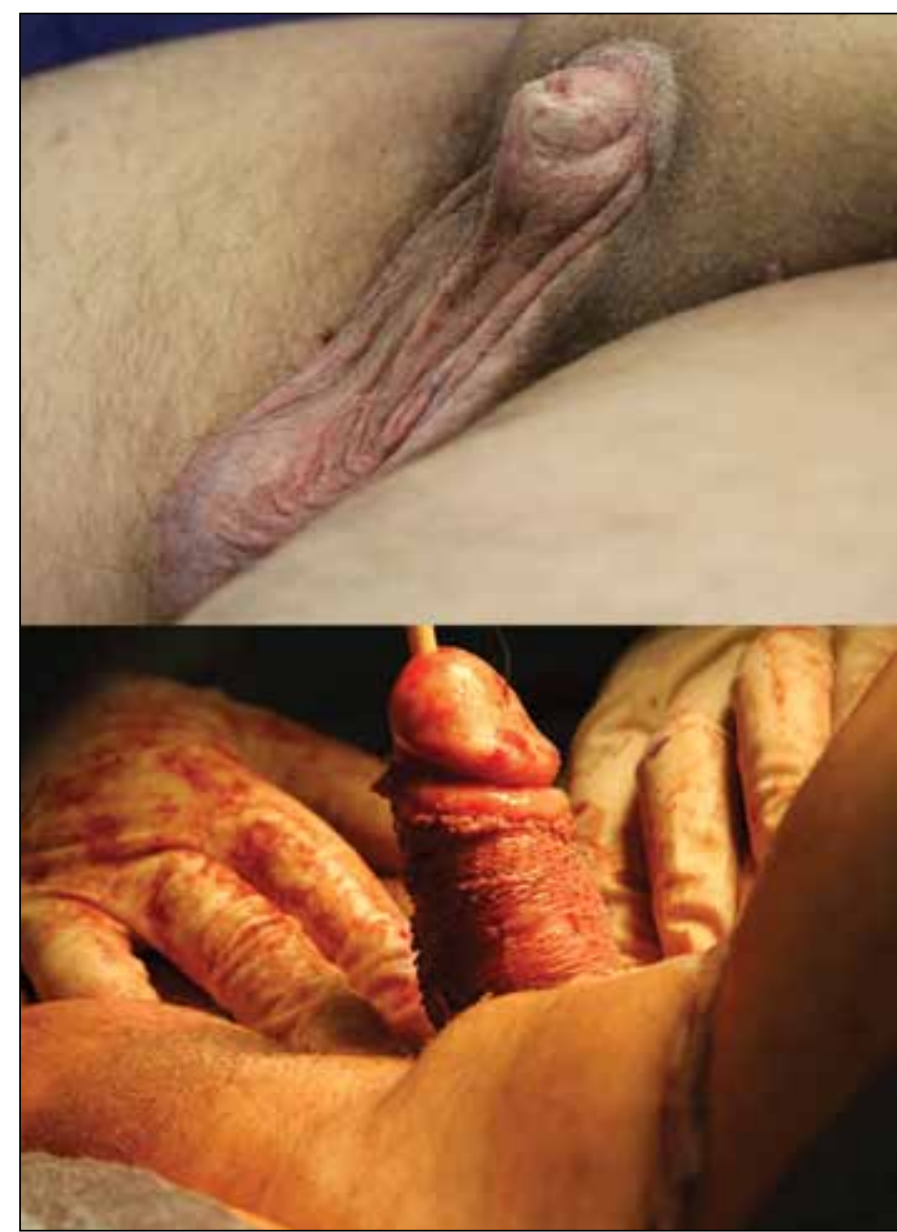

Fig. 1. Patient with concealed penis secondary to balanitis xerotica obliterans (BXO). Preoperatively (top), the patient exhibits near-complete concealment with significant scarring, while postoperative results (bottom) demonstrate preservation of penile length with completion of graft

\section{Results}

During the study period, a total of 11 patients underwent $\mathrm{CP}$ release and placement of meshed STSG. Mean patient age was 49 years (range 28-69), and mean graft size was $148 \mathrm{~cm}^{2}$ (range $80-400 \mathrm{~cm}^{2}$ ). Contributing etiologies for CP included pelvic trauma $(n=1)$, infections/necrosis following inflatable penile prosthesis (IPP) placement $(n=2)$, balanitis xerotica obliterans $(B X O)(n=3)$, morbid obesity $(n=2)$, and cicatricial band formation following circumcision or other types of penile surgery $(n=3)$ (Table 1$)$

Skin grafts were isolated either from the abdominal pannus (in cases of panniculectomy) or the lateral thighs. One patient underwent concomitant IPP placement, while two underwent subsequent prosthesis insertion. The majority of procedures (10/11) were primary CP releases, with one patient undergoing salvage therapy following a failed prior reconstruction with scrotal flap advancement.

At time of publication, none of the 11 patients needed further surgical management for CP. All patients at time of

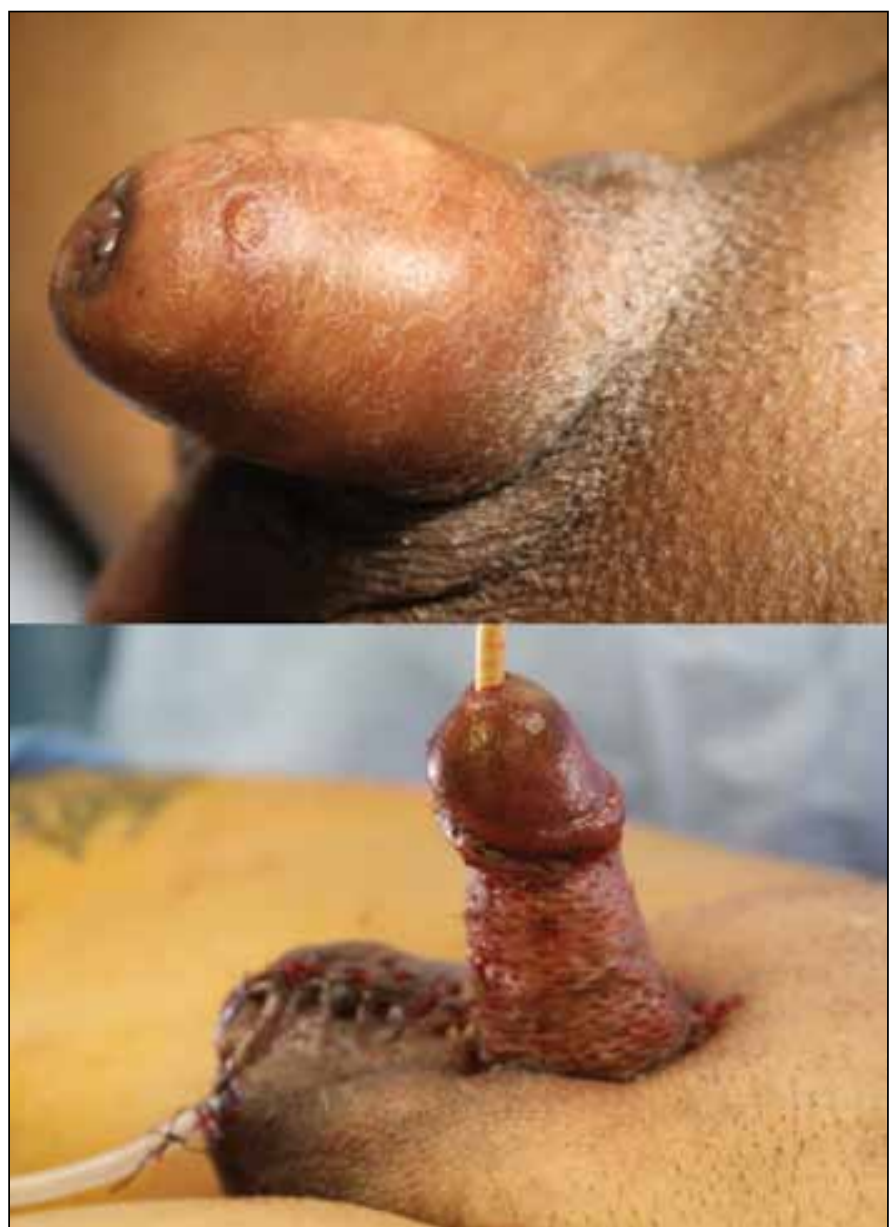

Fig. 2. Pre- (top) and postoperative (bottom) images of a patient with concealed penis secondary to iatrogenic instillation of silicone for girth enhancement.

clinic followup were subjectively able to urinate to completion without new lower urinary tract symptoms.

Immediate and delayed postoperative imaging was obtained to evaluate cosmesis and graft take/contraction (Figs. 1-5).

\section{Discussion}

$\mathrm{CP}$ represented a challenging clinical problem with need for surgical expertise in skin flap advancement and/or graft placement. In more complex cases, autologous grafting is a viable option for wound coverage. In our experience, the use of micro-fenestrated meshed STSG results in excellent graft take/survival and cosmesis. This method can be employed for either primary or salvage procedures.

The use of STSG for penile skin coverage has been previously described by Black et al. ${ }^{10}$ At our facility, we routinely perform a fenestrated meshing in an attempt to improve the likelihood of graft survival via enhanced imbibition and reduction of graft contracture, as some researchers have previously described. ${ }^{11}$ Meshed STSG have the benefit of complete drainage of any fluid collections and allow surgeons to 


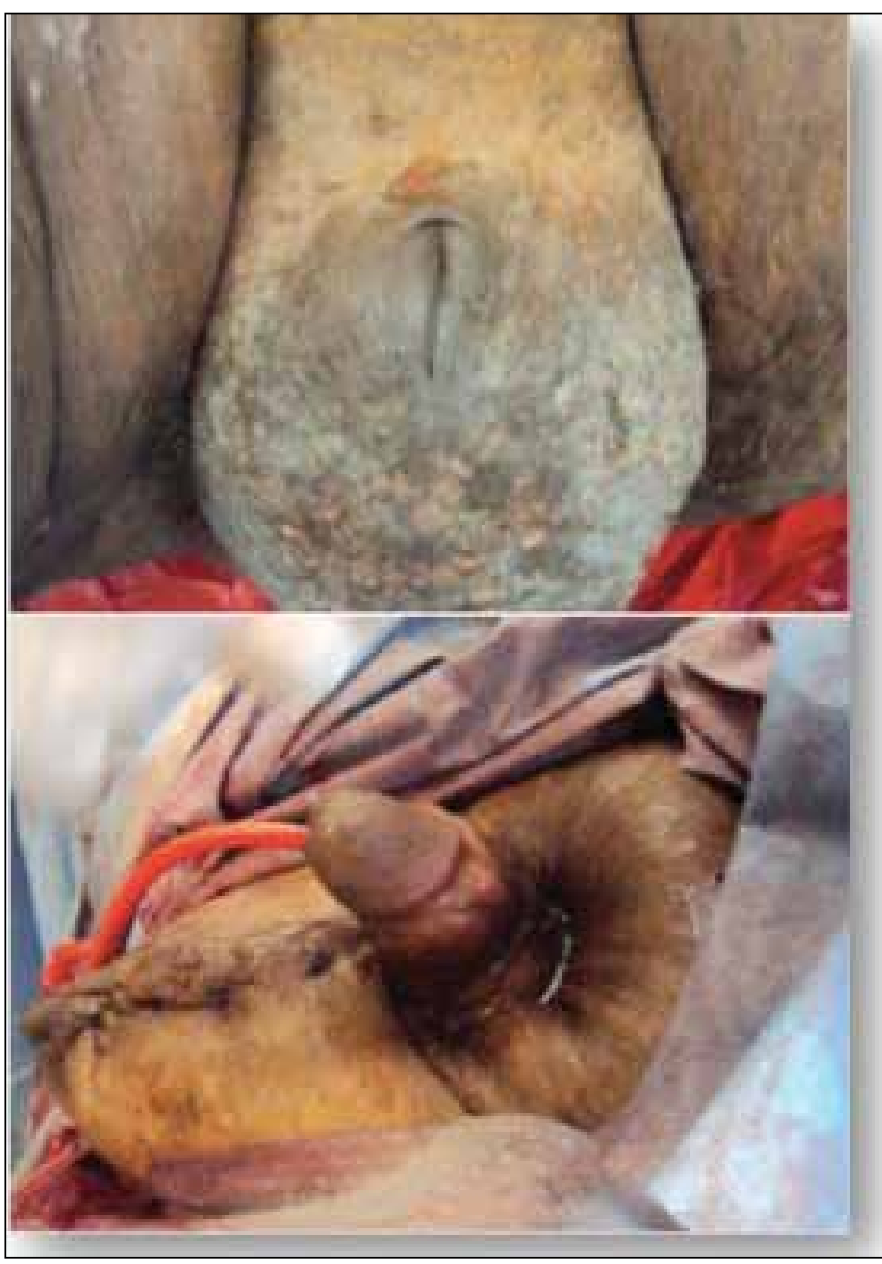

Fig. 3. Pre- (top) and postoperative (bottom) images demonstrating severe scrotal lymphedema and hidradenitis. Note the use of tacking sutures (bottom) placed subcutaneously to secure the skin to the base of the dorsal penile shaft.

minimize the amount of graft area that has to heal through secondary intention, which can result in a "pebbling" of the graft. The use of a fenestrated technique has been shown to allow adequate contouring to the graft bed while minimizing the "pebbling" effect of meshed grafts. ${ }^{12}$ Secondly, the use of a STSG allows for pliability during wound healing, especially in patients with nocturnal erectile function. Given the dynamic nature of penile tissue in men with normal erectile function, a STSG allows for stretching of the graft, which undoubtedly contributes to a reduction in graft contracture as opposed to a FTSG. We feel our technique minimizes the scarring process of graft wound healing. This result is demonstrated in the durability of the treatment, as none of these patients needed further treatment. This was especially important in the patients who had $\mathrm{CP}$ due to progressive infectious processes, such as $\mathrm{BXO}$.

The adjunctive use of a negative-pressure wound vacuum device reduces fluid accumulation under the graft and eliminates seroma formation, which increase the likelihood for graft success. ${ }^{10}$ Placement of a wound vac also enhances

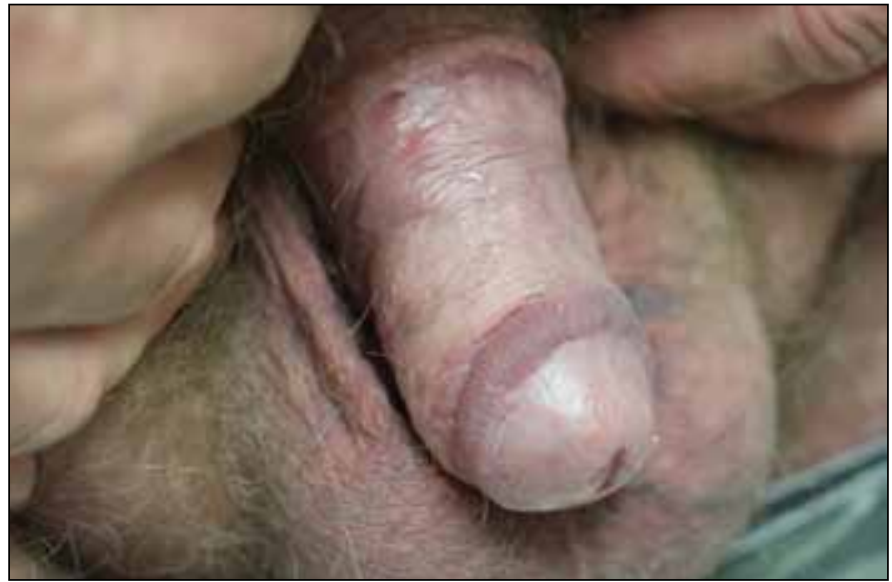

Fig. 4. Three-month postoperative result demonstrates excellent graft take and cosmetic result with no evidence of graft contracture.

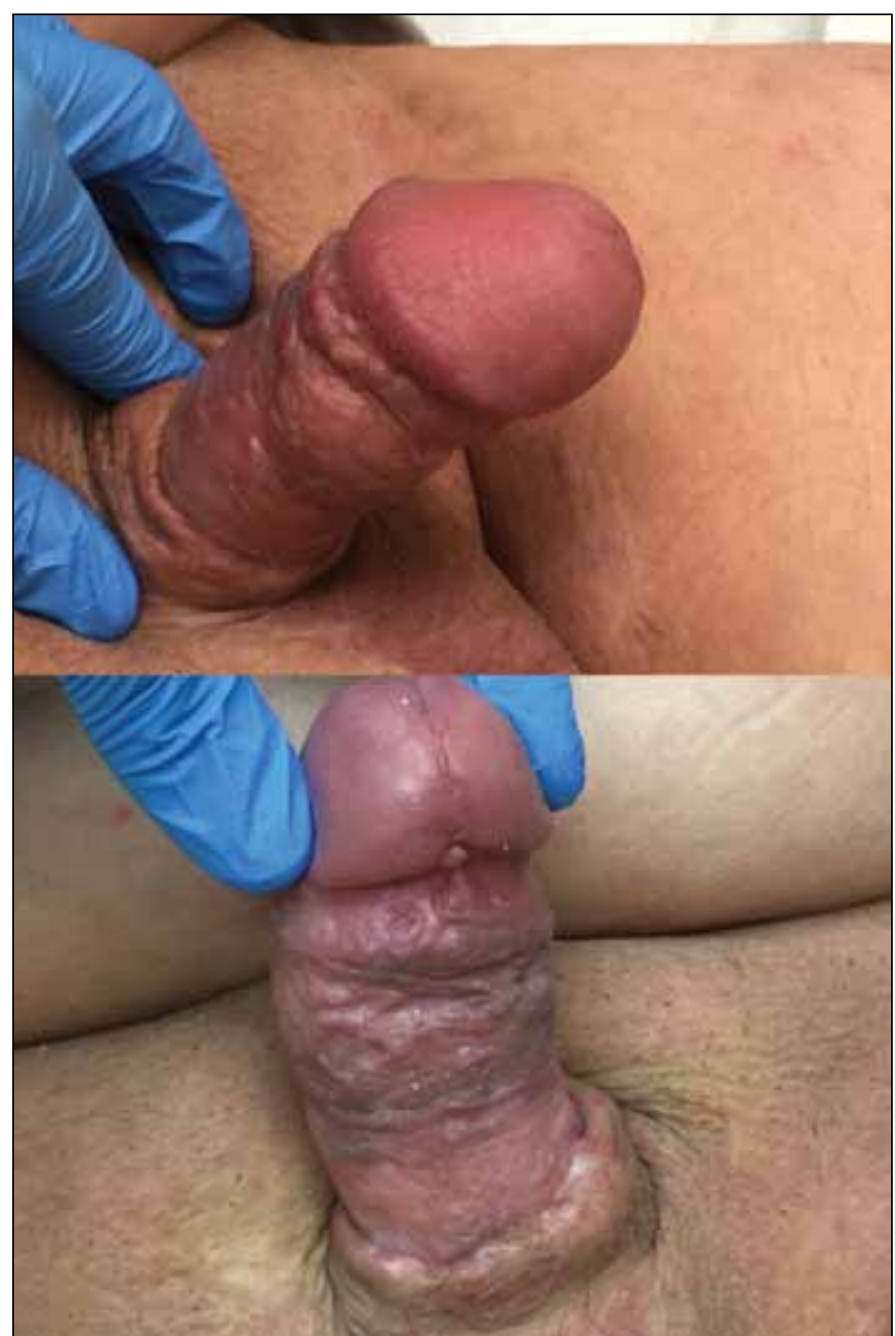

Fig. 5. One-year followup images show maintenance of penile protrusion and good cosmesis of penile shaft. 
graft contouring to the wound bed to further enhance cosmetic appearance and overall success.

Given the surgical complexity of $\mathrm{CP}$, the operating surgeon needs to be comfortable with a variety of techniques for wound coverage, including transfer tissue grafts and advancement grafts. In addition to a number of other surgical procedures in the literature, the use of meshed STSG as penile skin coverage is a viable option after extensive debridement and generally results in an excellent overall cosmetics and preserved function. Our series demonstrates that meshed STSG can be used in a variety of CP situations and needs to be considered by surgeons performing reconstructive penile procedures.

Competing interests: Dr. Hellstrom has been a consultant or advisor for Abbvie, Allergan, Antares, Astellas, Boston Scientific, Coloplast, Endo, Lipocine Inc., Pfizer, and Repros Therapeutics; a speaker for Endo and Menarini; a board member for NIH and Theralogix; and has participated in clinical trials for Coloplast, Endo, and the New England Research Institutes, Inc. The remaining authors report no competing personal or financial interests.

This paper has been peer-reviewed.

\section{References}

1. Donatucci CF, Ritter EF. Management of the buried penis in adults. J Urol 1998;159:420-4. http:// dx.doi.org/10.1016/S0022-5347(01)63939-9

2. Pestana IA, Greenfield JM, Walsh M, et al. Management of "buried" penis in adulthood: An overview. Plast Reconstr Surg 2009;124:1186-95. http://dx.doi.org/10.1097/PRS.0b013e3181b5a37f

3. Higuchi TT, Yagamuchi Y, Wood HM, et al. Evaluation and treatment of adult concealed penis. Curr Urol Rep 2012;13:277-84. http://dx.doi.org/10.1007/s1 1934-012-0255-z

4. Morey AF, Meng MV, McAninch JW. Skin graft reconstruction of chronic genital lymphedema. Urology 1997;50:423-6. http://dx.doi.org/10.1016/S0090-4295(97)00259-8

5. Alter GJ, Ehrlich RM. A new technique for correction of the hidden penis in children and adults. J Urol 1999;161:455-9. http://dx.doi.org/10.1016/S0022-5347(01)61922-0

6. Alter GJ. Surgical techniques: Surgery to correct hidden penis. J Sex Med 2006;3:939-42. http://dx.doi. org/10.1111/.i.1743-6109.2006.00298.x

7. Gillett MD. Split-thickness skin graft for the management of concealed penis. J Urol 2005;173:579-82. http://dx.doi.org/10.1097/01.ju.0000149606.27158.fa

8. Wessells H, Long L. Penile and genital injuries. Urol Clin North Am 2006;33:117-26. http://dx.doi. org/10.1016/i.ucl.2005.11.003

9. Tang SH, Kamat D, Santucci RA. Modern management of adult-acquired buried penis. Urology 2008;72:124-7. http://dx.doi.org/10.1016/i.urology.2008.01.059

10. Black $P C$, Freidrich JB, Engrav $L H$, et al. Meshed unexpanded split-hickness skin grafting for reconstruction of penile skin loss. J Urol 2004;172:976-9. http://dx.doi.org/10.1097/01.ju.0000133972.65501.44

11. Wessells H. Genital skin loss: Unified reconstructive approach to a heterogeneous entity. World I Urol 1999;17:107-14. http://dx.doi.org/10.1007/s003450050115

12. Wokes, JE, Ali-Khan A. Microfenestrated split thickness skin grafts: An underused technique? Ann R Coll Surg Engl 2012;94:447. http://dx.doi.org/10.1308/003588412X133734053860150

Correspondence: Dr. Wayne Hellstrom, Tulane University Health Sciences Center, Department of Urology, New Orleans, LA, United States; whellst@tulane.edu 